\title{
Myocardial protection in beating heart cardiac surgery: I: Pre- or postconditioning with inhibition of es-ENT1 nucleoside transporter and adenosine deaminase attenuates post-MI reperfusion-mediated ventricular fibrillation and regional contractile dysfunction
}

\author{
Anwar Saad Abd-Elfattah, MS, PhD, FAHA, AFSTS, ${ }^{\mathrm{a}}$ Hamdy Aly, MD, PhD, ${ }^{\mathrm{b}}$ Scott Hanan, MD, ${ }^{\mathrm{a}}$ and \\ Andrew S. Wechsler, MD, FACS ${ }^{\mathrm{C}}$
}

\begin{abstract}
Objective: To determine the role of the p-nitrobenzylthioinosine-sensitive equilibrative nucleoside transporter 1 (es-ENT1) in postmyocardial infarction reperfusion injury-mediated ventricular fibrillation and regional dysfunction. We used erythro-9 (2-hydroxy-3-nonyl)-adenine and p-nitrobenzylthioinosine to inhibit both adenosine deamination and transport in a canine model of off pump acute myocardial infarction.
\end{abstract}

\begin{abstract}
Methods: Anesthetized adult dogs $(\mathrm{n}=37)$, instrumented to monitor the percentage of systolic segmental shortening and wall thickening using sonomicrometry, underwent 90 minutes of left anterior descending coronary artery occlusion and 120 minutes of reperfusion. Myocardial coronary blood flow, adenosine triphosphate pool, infarct size, and the incident of ventricular fibrillation and cardioversion were also measured. The dogs received an intravenous infusion of the vehicle (control) or $100 \mu \mathrm{M}$ of erythro-9 (2-hydroxy-3-nonyl)-adenine and $25 \mu \mathrm{M}$ p-nitrobenzylthioinosine before ischemia (preconditioning group) or just before reperfusion (postconditioning group).
\end{abstract}

Results: In the control group, adenosine triphosphate depletion was associated with the accumulation of more inosine than adenosine during ischemia and washed out during reperfusion. Myocardial adenosine and inosine were the major nucleosides in the pre- and postconditioning groups during ischemia and remained detectable during reperfusion. In both groups, recovery of systolic segmental shortening and wall thickening and a reduction in the incidence of ventricular fibrillation $(P<.05$ vs the control group) coincided with retention of myocardial nucleosides. The infarct size in the 3 groups was not significantly different, independent of myocardial blood flow during ischemia.

Conclusions: Preconditioning or postconditioning with erythro-9 (2-hydroxy-3-nonyl)-adenine/p-nitrobenzylthioinosine significantly reduced the incidence of ventricular fibrillation and cardioversion and attenuated regional contractile dysfunction mediated by postmyocardial infarction reperfusion injury. It is concluded that p-nitrobenzylthioinosine-sensitive equilibrative nucleoside transporter 1 played a major role in these events. (J Thorac Cardiovasc Surg 2012;144:250-5)

Supplemental material is available online.

\footnotetext{
From the Division of Cardiothoracic Surgery, ${ }^{a}$ Department of Surgery, Virginia Commonwealth University Medical Center, Richmond, Va; Ein-Shams University School of Medicine, ${ }^{\mathrm{b}}$ Cairo, Egypt; and Drexel University Medical Center, ${ }^{\mathrm{c}}$ Philadelphia, $\mathrm{Pa}$.

Supported in part by National Institutes of Health grant R01 HL05-1090 (to A. S. Abd-Elfattah).

Disclosures: Authors have nothing to disclose with regard to commercial support.

Received for publication June 15, 2011; revisions received Sept 14, 2011; accepted for publication Oct 4, 2011; available ahead of print Feb 13, 2012.

Address for reprints: Anwar Saad Abd-Elfattah, MS, PhD, FAHA, AFSTS, Department of Surgery, Virginia Commonwealth University Medical Center, 1200 East Broad Street, West Hospital, 7-308 West Wing, Richmond, VA 23298-0068 (E-mail: aabdelfattah@mcvh-vcu.edu).

0022-5223/\$36.00

Copyright (c) 2012 by The American Association for Thoracic Surgery doi:10.1016/j.jtcvs.2011.10.095
}

Reperfusion of the ischemic heart is a prerequisite intervention for myocardial salvage and patient survival. ${ }^{1}$ In addition to preexisting ischemic injury, reperfusion of an infarcted heart creates more aggressive conditions that trigger a surge of free radicals and promote ventricular arrhythmia and fibrillation. Therefore, targeting postischemic reperfusion injury ${ }^{2}$ that occurs with thrombolytic therapy, percutaneous coronary intervention, and coronary artery bypass grafting $(\mathrm{CABG})$ represents a major scientific and clinical challenge and opportunity.

Ischemia depletes adenosine triphosphate (ATP), transiently elevates adenosine, and progressively accumulates inosine (Figure E1). On reperfusion, both adenosine and inosine are released from the ischemic cells by way of the p-nitrobenzylthioinosine (NBMPR)-sensitive equilibrative nucleoside transporter (es-ENT1), where they are converted to hypoxanthine and xanthine. Both metabolites are substrates for xanthine oxidase, catalyzing the formation of 


$$
\begin{aligned}
& \text { Abbreviations and Acronyms } \\
& \begin{aligned}
\text { ATP } & =\text { adenosine triphosphate } \\
\text { CABG } & =\text { coronary artery bypass grafting } \\
\text { EHNA } & =\text { erythro-9 (2-hydroxy-3-nonyl)- } \\
& \text { adenine } \\
\text { es-ENT1 } & \text { p-nitrobenzylthioinosine-sensitive } \\
& \text { equilibrative nucleoside transporter } 1 \\
\text { LAD } & =\text { left anterior descending } \\
\text { MI } & =\text { myocardial infarction } \\
\text { NBMPR } & =\text { p-nitrobenzylthioinosine } \\
\text { SS } \% & =\text { segmental shortening } \\
\text { VFib } & =\text { ventricular fibrillation } \\
\text { WT } \% & =\text { wall thickening }
\end{aligned}
\end{aligned}
$$

with an initial intravenous injection of $35 \mathrm{mg} / \mathrm{kg}$ sodium pentobarbital (Abbott Laboratories, Chicago, Ill) and intubated and ventilated using a Bennett MA1 respirator (Puritan-Bennett, Berkeley, Calif). Next, a median sternotomy was performed, and the heart was supported in a pericardial sling. The anterior and posterior segments of the left ventricle were instrumented with 2 pairs of lead titanate zirconate piezoelectric crystals to monitor systolic segmental shortening $(\mathrm{SS} \%, 10 \mathrm{~mm})$ and wall thickening (WT\%, epicardium to endocardium) using a pulse transit sonomicrometry system (Triton Technology, San Diego, Calif). Millar transducers were placed intraventricularly by way of the apex and into the carotid artery to monitor the left ventricular and systemic pressures, respectively. The analog data were digitized at $200 \mathrm{~Hz}$ and stored on a hard disk on a personal computer and subsequently analyzed using interactive Crunch software developed in our laboratory. Regional myocardial contractility and wall thickening were measured at steady state conditions. The results were calculated as the percentage of change in the end-diastolic length in both $\mathrm{SS} \%$ and $\mathrm{WT} \%$ for each beat (10-25 beats). The body and heart temperatures were maintained at $37^{\circ} \pm 1^{\circ} \mathrm{C}$. The right phrenic nerve was transected, and the sinoatrial node was crushed and then paced at $150 \mathrm{bpm}$. A silastic snare was placed around the left anterior descending (LAD) artery just before the first diagonal branch. Porcine-based heparin was intravenously injected (400 U/kg) as an initial bolus followed by $200 \mathrm{U} / \mathrm{kg} / \mathrm{hr}$ (Elkins-Sinn, Cherry Hill, NJ). Arterial blood gases, $\mathrm{pH}$, and hematocrit were routinely determined and maintained (partial oxygen pressure, $100-140 \mathrm{~mm} \mathrm{Hg}$; partial carbon dioxide pressure, $30-40 \mathrm{~mm} \mathrm{Hg}$; $\mathrm{pH}, 7.32-7.48$; and hematocrit, about $30 \%$ ).

\section{Assessment of Adenine Nucleotide Pool Metabolism}

Transmural Tru-Cut needle biopsy specimens (5-10 mg) were obtained at baseline before and after drug administration, during LAD artery occlusion, and after 120 minutes of reperfusion, as previously described. ${ }^{11}$

\section{Regional Myocardial Blood Flow and Infarct Size}

Coronary blood flow was measured using nonradioactive color microspheres (NuFlow Hydron-Coat, Irvine, Calif), as previously described ${ }^{11,12}$ and published on line (see E-Methods).

selective targeting of purine-mediated reperfusion injury would lead to site-specific elevation and compartmentalization of free adenosine and inosine in ischemic cells, providing localized protection against reperfusion-mediated injury. Selective targeting of purine-mediated reperfusion injury was achieved by inhibiting adenosine deaminase with erythro-9 (2-hydroxy-3-nonyl)-adenine (EHNA) and blocking adenosine transport with NBMPR. The results demonstrated that pharmacologic pre- and postconditioning with EHNA and NBMPR significantly improved the recovery of function and reduced the incidence of ventricular fibrillation (VFib).

\section{METHODS}

The biochemical reagents, EHNA and NBMPR, were obtained from Sigma-Aldrich (St. Louis, Mo).

\section{Animal Model}

The experiments conformed to the Guidelines for the Care and Use of Laboratory Animals published by the US National Institutes of Health (publication no. 5377-3; available at http://www.nap.edu/catalog/5140. html.

\section{Surgical Procedures and Model of Acute MI}

A total of 37 microfilaria-free adult dogs, of either sex and weighing $22.3 \pm 2 \mathrm{~kg}$, were used in the present study. The dogs were anesthetized

\section{Experimental Protocol}

Myocardial blood flow, systolic SS\%, WT\%, and myocardial biopsy were obtained at baseline, during LAD occlusion, and after reperfusion. Matching measurements and biopsies were obtained from the nonischemic posterior side of the left ventricle. The LAD coronary artery was snared for 90 minutes. A single bolus of the vehicle (saline and $0.05 \%$ dimethylsulphoxide) or vehicle solution containing $100 \mu \mathrm{M}$ EHNA and $25 \mu \mathrm{M}$ NBMPR $(50 \mathrm{~mL})$ was administered intravenously 5 minutes before LAD artery occlusion (preconditioning group) or just before reperfusion (postconditioning group).

\section{Statistical Analysis}

The data are presented as the mean \pm standard error of the mean. Sequential measurements were compared using analysis of variance for repeated measures using SAS (SAS Institute, Cary, NC). When significant differences were detected between the groups' pairs of mean values, they were compared using Tukey's post hoc tests. Differences were considered significant if the probability value for comparison of least squares means was less than 0.05 ; the $\mathrm{F}$ ratios are provided with the figures. The frequency of VFib was analyzed using Fisher's exact probability test.

\section{RESULTS}

\section{Exclusions}

The exclusions are listed in Table E1. Dogs with significant coronary blood flow ( $>20 \%$ of baseline $2.1 \pm 0.1 \mathrm{~mL} / \mathrm{min} / \mathrm{g}$ ) 
during LAD artery occlusion and no or small infarction $(0-5 \%)$ were rejected from the study ( 7 of the $37 \mathrm{dogs}$ ). All dogs ( $\mathrm{n}=8$ in each group) survived to the end of reperfusion period, despite events of VFib during reperfusion.

\section{Myocardial ATP}

At baseline, the myocardial ATP levels were as follows: control group, $30 \pm 3 \mathrm{nmol} / \mathrm{mg}$ protein; preconditioning group, $28 \pm 3 \mathrm{nmol} / \mathrm{mg}$ protein; postconditioning group, $29 \pm 2 \mathrm{nmol} / \mathrm{mg}$ protein; and nonischemic posterior left ventricular segment, $30 \pm 2 \mathrm{nmol} / \mathrm{mg}$ protein. Ninety minutes of LAD artery occlusion decreased the myocardial ATP levels equally in all groups $(>70 \%)$. The ATP level in the control, preconditioning, and postconditioning groups was $4.8 \pm 2,7.5 \pm 2$, and $8.0 \pm 2 \mathrm{nmol} / \mathrm{mg}$ protein, respectively $(P<.01$ vs baselines). The circumflex vascular bed had normal ATP levels. Unlike the control and postconditioning groups, the ATP levels partially recovered in the preconditioning group, to $11.3 \pm 3$ and $13.3 \pm 2 \mathrm{nmol} / \mathrm{mg}$ protein at the end of 30 and 120 minutes of reperfusion. respectively $(P<.05$ vs baseline and other groups, analysis of variance, $\mathrm{F}=5.87)$.

\section{Myocardial Adenosine and Inosine}

Adenosine and inosine were not detectable in the myocardial tissue before LAD artery occlusion in any group (Figure 1). At the end of 90 minutes of occlusion, a low adenosine level was found in the control group, with a marked increase in inosine $(5.8 \pm 0.40 \mathrm{nmol} / \mathrm{mg}$ protein; Figure $1, B)$. In the preconditioning group, both adenosine and inosine progressively accumulated, reaching peaks at 90 minutes of LAD artery occlusion $(7.8 \pm 0.7$ and $3.3 \pm$ $0.5 \mathrm{nmol} / \mathrm{mg}$ protein, respectively). Adenosine and inosine declined but remained significantly detectable during reperfusion. Similar to the control group, adenosine was low in the postconditioning group at the end of 90 minutes of LAD artery occlusion $(0.2 \pm 0.1 \mathrm{nmol} / \mathrm{mg}$ protein $)$; inosine was $7.3 \pm 0.6 \mathrm{nmol} / \mathrm{mg}$ protein. Unlike the control group, inosine remained detectable during reperfusion in the postconditioning group during reperfusion.

\section{Regional Systolic SS\% and WT $\%$}

The baseline SS\% and WT\% in the control, preconditioning, and postconditioning groups was $22 \% \pm 3 \%$, $20 \% \pm 4 \%$, and $19 \% \pm 2 \%$ and $24 \% \pm 5 \%, 19 \% \pm$ $3 \%, 21 \% \pm 3 \%$, and $22 \% \pm 3 \%$, respectively. At the onset of LAD artery occlusion, systolic SS\% switched from positive shortening to a negative paradoxical bulging (Figure 2, A) and a concomitant profound wall thinning (Figure $2, B$ ) in all groups. In the control group, SS\% was $-25 \% \pm 3 \%$ and $\mathrm{WT} \%$ was $-77 \% \pm 3 \%$ at $90 \mathrm{~min}-$ utes of ischemia and remained depressed during reperfusion (Figure 2, B). The change in $\mathrm{WT} \%$ was almost threefold greater than the change in $\mathrm{SS} \%$ at the end of
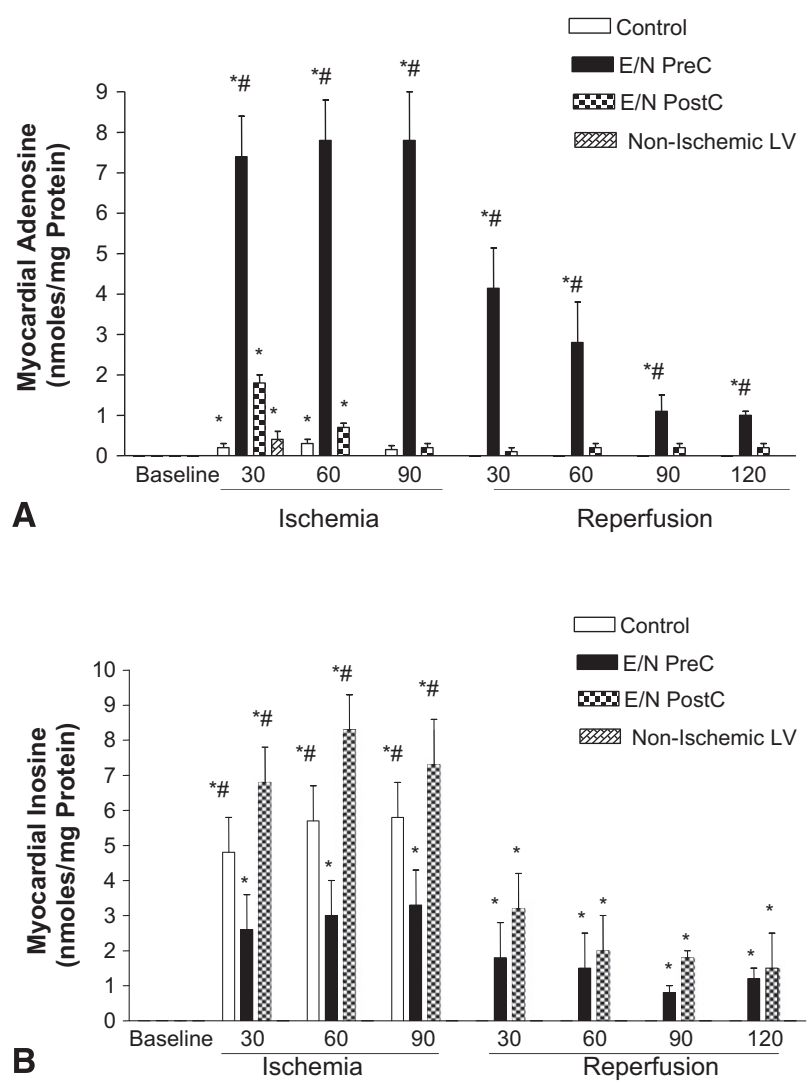

FIGURE 1. Effect of erythro-9 (2-hydroxy-3-nonyl)-adenine/p-nitrobenzylthioinosine (EHNA/NBMPR) on (A) myocardial adenosine and (B) inosine in a canine model of 90 minutes of left anterior descending ( $L A D)$ artery occlusion and reperfusion showing statistically significant differences between groups with respect to $(\mathrm{A})$ adenosine $(P<.001$, analysis of variance, $\mathrm{F}=11.81 ; * P<.05$ versus baseline and control group, $\# P<.05$ versus all other groups, analysis of variance; $\mathrm{n}=8 \mathrm{dogs} / \mathrm{each}$ group) and (B) inosine ( $P<.01,2$-way analysis of variance, $\mathrm{F}=8.85$; $* P<.05$ versus baseline and control group, $\# P<.05$ versus all other groups, $\mathrm{n}=8 \mathrm{dogs}$ /group). E/N, EHNA/NBMPR; PreC, preconditioning; Post $C$, postconditioning; $L V$, left ventricle.

ischemia. In the preconditioning group, the SS\% $(-18 \%$ $\pm 2 \%)$ and $\mathrm{WT} \%(-50.3 \% \pm 2 \%)$ were also similar to those of the control group. A marked recovery was observed in SS\% in this group, reaching $+75 \% \pm 2 \%$ and $+78.4 \% \pm 4 \%$ at 30 and 120 minutes of reperfusion, respectively. The $\mathrm{WT} \%$ in this group was less negative $(-15 \% \pm 2 \%)$ at 30 minutes of reperfusion than that at the end of ischemia $(-55 \% \pm 4 \%)$ and WT\% had improved at the end of reperfusion $(25 \% \pm 4 \%)$. In the postconditioning group, $\mathrm{SS} \%$ at the end of ischemia was $-22 \%$ $\pm 3 \%$ but had recovered to $+30 \% \pm 3 \%$ and $+53 \% \pm 3 \%$ after 30 and 120 minutes of reperfusion, respectively. The WT $\%$ changed from $-55 \% \pm 3 \%$ at the end of ischemia to a less negative $-36 \% \pm 5 \%$ and then to positive thickening $(12 \% \pm 3 \%)$ at 30 and 120 minutes of reperfusion, respectively. 

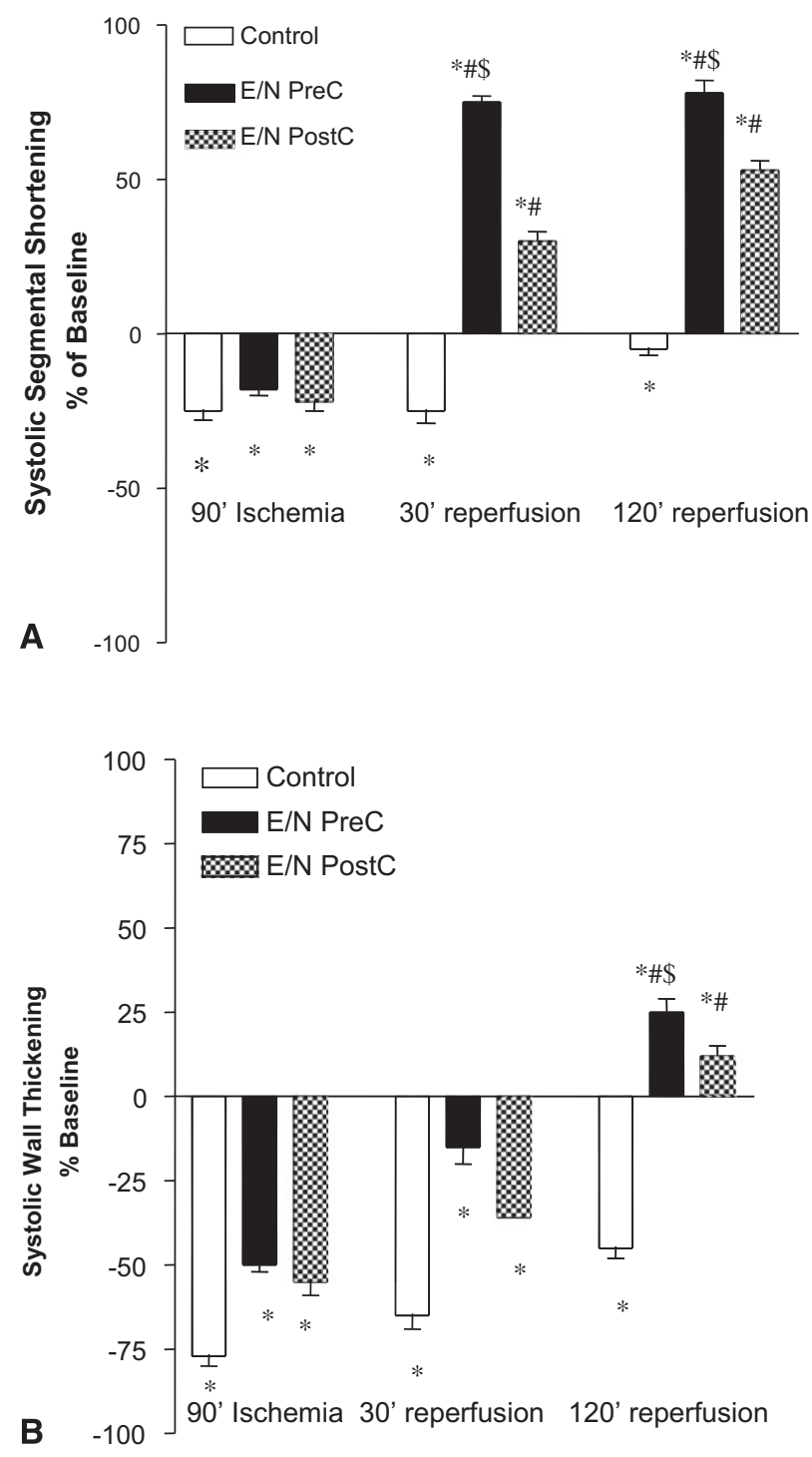

FIGURE 2. A, Effect of erythro-9 (2-hydroxy-3-nonyl)-adenine/p-nitrobenzylthioinosine (EHNA/NBMPR) on (A) systolic segmental shortening $(S S \%)$ and (B) wall thickening $(W T \%)$ in a canine model of 90 minutes of left anterior descending $(L A D)$ artery occlusion and reperfusion showing statistically significant differences between groups with respect to (A) segmental shortening $(P<.01$, analysis of variance, $\mathrm{F}=8.3 ; * P<.05$ vs. baseline, $\# P<.05$ vs control group, $\$ P<.05$ vs postischemic treatment group, analysis of variance; $\mathrm{n}=8 \mathrm{dogs} /$ group $)$ and (B) wall thickening $(P<.01$, analysis of variance, $\mathrm{F}=9.18 ; * P<.05$ vs baseline, $\# P<.05$ vs control group, $\$ P<.05$ vs postischemic treatment group; $\mathrm{n}=8$ dogs/group). E/N, EHNA/NBMPR; PreC, preconditioning; Post $C$, postconditioning.

\section{Ventricular Fibrillation}

The incidence of fibrillation was recorded during postischemic reperfusion. VFib was more frequent at 25 to 30 minutes of reperfusion. All hearts that were resuscitated with hand massage and electric cardioversions completed the study (Figure 3,A). One or more episodes of VFib that required cardioversion occurred in 6 of 8 hearts in the
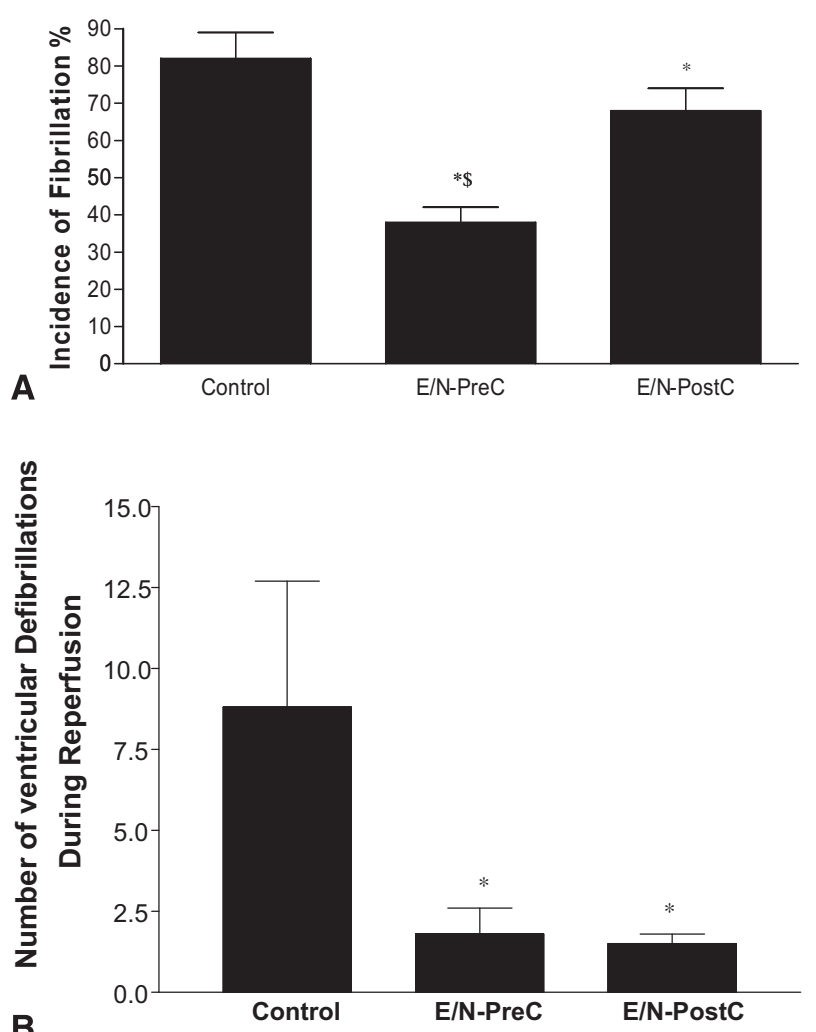

FIGURE 3. Effect of erythro-9 (2-hydroxy-3-nonyl)-adenine/p-nitrobenzylthioinosine (EHNA/NBMPR) on the incidence of (A) reperfusionmediated ventricular fibrillation $(V F i b)$ and (B) the number of defibrillation attempt to resuscitate the heart in a canine model of 90 minutes of left anterior descending $(L A D)$ artery occlusion and reperfusion showing statistically significant differences between groups $(\mathrm{A}, P<.05$, analysis of variance, $\mathrm{F}=4.02 ; * P<.05$ vs control group, $\$ P<.05$ vs postischemic treatment group, Fisher's exact test; $\mathrm{n}=8 \mathrm{dogs}$ /group; and $\mathrm{B}, P<.05$, analysis of variance, $\mathrm{F}=6.80$; $* P<.05$ vs control group, $\$ P<.05$ vs postischemic treatment group, Fisher's exact test; $\mathrm{n}=8 \mathrm{dogs}$ (group).

control group, 2 of 8 in the preconditioning group, and 4 of 8 in the postconditioning group $(P<.05$, Fisher's exact probability test). The number of electric cardioversions needed to achieve successful resuscitation (Figure 3, B) was also lower in the EHNA/NBMPR-treated groups (preconditioning, $1.8 \pm 0.8$, and postconditioning, $1.5 \pm 0.3$ ) than in the control group $(8.8 \pm 4 ; P<.05)$.

\section{Myocardial Blood Flow and Infarct Size}

The myocardial blood flow before LAD artery occlusion was $2.2 \pm 0.2,2.1 \pm 0.1$, and $2.01 \pm 0.2 \mathrm{~mL} / \mathrm{min} / \mathrm{g}$ in the control, preconditioning, and postconditioning groups, respectively ( $\mathrm{n}=8 /$ group). The coronary blood flow during LAD artery occlusion was $0.14 \pm 0.05,0.12 \pm 0.03$, and $0.15 \pm 0.04 \mathrm{~mL} / \mathrm{min} / \mathrm{g}$ in the control, preconditioning, and postconditioning groups, respectively $(P=\mathrm{NS})$. The ischemic area (risk area) relative to the total area of the left ventricle was $39 \% \pm 6 \%, 37 \% \pm 4 \%$, and $32 \% \pm 5 \%$ 
in the control, preconditioning, and postconditioning groups, respectively. The infarct size normalized to the risk area was not significantly different among the 3 groups $(35 \% \pm 5 \%, 24 \% \pm 7 \%$, and $28 \% \pm 6 \%$ for the control, preconditioning, and postconditioning groups, respectively; $P=.08)$.

\section{DISCUSSION}

The hypothesis underlying the present study was that ATP catabolites (adenosine and inosine), accumulating during ischemia and released on reperfusion by way of the esENT1, contribute to post-MI reperfusion injury-mediated VFib and contractile dysfunction. A combination of EHNA and NBMPR was used to modulate the adenosine and inosine metabolism and compartmentalization during ischemia and reperfusion. The unique feature of pre- and postconditioning with EHNA/NBMPR is that their actions are confined within the ischemic myocardium without affecting nonischemic tissues. Because acute MI is irreversible, new modalities that target post-MI reperfusion injury and improve functional recovery despite MI represent a clinical challenge and opportunity.

ATP depletion during LAD artery occlusion was similar in all groups, suggesting that EHNA/NBMPR intervention does not prevent ischemic injury, per se, but instead targets reperfusion injury by modulating adenosine and inosine metabolism and transport during ischemia and reperfusion. Numerous investigators have characterized the phenomena of classic ischemic preconditioning ${ }^{13}$ and postischemic preconditioning ${ }^{14}$ in various models, demonstrating that endogenous adenosine formation and release from ischemic cells is required for activation of the adenosine receptor subtypes that mediate the anti-infarction signaling mechanisms. ${ }^{15,16}$ Because NBMPR blocks the release and uptake of adenosine and inosine $\left(\mathrm{K}_{\mathrm{i}}=0.05 \mathrm{nM}\right)$, the entrapped intracellular adenosine is presumably not accessible to the membrane surface adenosine receptors. This could explain, in part, the insignificant reduction in the infarct size observed in the preconditioning and postconditioning groups. In the postconditioning group, delaying the administration of EHNA/NBMPR to the end of ischemia but before reperfusion also entrapped more inosine than adenosine and was associated with improved recovery of regional function and a reduced incidence of VFib but not infarct size. In isolated perfused rabbit heart preparations, Walsh et $\mathrm{al}^{17,18}$ have demonstrated that pretreatment with EHNA/NBMPR not only prevented adenosine and inosine release during hypoxia but also abolished the infarct size-limiting effects of ischemic preconditioning. Because preexisting MI increases the risk of VFib and contractile failure, pre- and postconditioning with EHNA/NBMPR would improve the outcomes with post-MI reperfusion. Pharmacologic pre- plus postconditioning is the more relevant clinical application in targeting reperfusion injury after MI than ischemic pre- and postconditioning. The MI induced by LAD coronary artery occlusion in dogs is usually more pronounced toward the endocardium than toward the mid- and epicardium; a phenomenon known as "wave front." This could explain, in part, the improved recovery of regional shortening monitored by sonocrystals placed between the epi- and midcardium, despite endocardial infarction. This also might have affected the recovery of transmural wall thickening monitored by crystals placed between the epi- and endocardium.

The mechanisms by which EHNA/NBMPR improve contractile recovery and attenuate fibrillation could be related, in part, to attenuation of free radical production derived from adenosine and inosine catabolism during reperfusion. The partial recovery of ATP during reperfusion in the preconditioning group has confirmed that adenosine was mainly localized in an intracellular compartment. Because preconditioning with EHNA/NBPR entraps high levels of adenosine, we postulated that the entrapped intracellular adenosine triggers unknown intracellular mechanisms of protection. Recently, Grube et $\mathrm{al}^{19}$ reported localization of the adenosine $\mathrm{A} 2 \mathrm{~B}$ receptor inside cardiac cells. In an accompanying study, ${ }^{20}$ we demonstrated that 8-cyclopentyl-1,3-dipropyl-xanthine, selective A1 receptor antagonist, or 8-(p-sulfophenyl)theophyline, the nonselective adenosine A1, A2A, A2B, A3 receptor antagonist, slightly reduced but did not abolish EHNA/NBMPRmediated cardiac functional recovery. Xi et $\mathrm{al}^{21}$ and Urmaliya et $\mathrm{a}^{22}$ have recently demonstrated that activation of the adenosine $\mathrm{A} 1$ receptor is dependent on cooperative activation of both $\mathrm{A} 2 \mathrm{~A}$ and $\mathrm{A} 3$ receptors. However, the role of the $\mathrm{A} 2 \mathrm{~A}, \mathrm{~A} 2 \mathrm{~B}$, and $\mathrm{A} 3$ receptors in EHNA/NBMPRmediated protection needs to be elucidated with selective agonists and antagonists.

In clinical settings, emergent thrombolytic therapy, percutaneous coronary intervention, and/or CABG are performed to restore blood perfusion to the ischemic myocardium as early as possible. In these cases, we believe that pre- and postconditioning with EHNA/NBMPR might not reduce preexisting MI but targets post-MI-mediated complications associated with reperfusion injury. These drugs could be infused intravenously or by intracoronary administration using the transcatheters before coronary intervention. Previous clinical trials have demonstrated the safety and efficacy of exogenous adenosine as an adjunct to cold cardioplegia during $\mathrm{CABG}^{23}$ and as an adjuvant to thrombolytic therapy in the Acute Myocardial Infarction Study of Adenosine (AMISTAD) trials. ${ }^{24}$ In the latter trial, a reduction in the infarct size was observed in the early, but not late, MI and only at a high dose of adenosine $(70 \mu \mathrm{g} / \mathrm{mL} /$ $\min$ for 3 hours). However, the over all mortality was not affected by adenosine therapy. Because adenosine has a short half life in humans and animals (seconds), higher doses of adenosine were used to reach pharmacologic efficacy. 
Adenosine deamination also increases the levels of unwanted free radical substrates for the vascular xanthine oxidase. Therefore, EHNA would prolong the half life of exogenous adenosine and reduce the dose of adenosine in future clinical trials. Our intervention introduces the concept of "global myocardial protection" during off-pump beating heart CABG surgery without hypothermia, cardioplegic arrest on pump. The infusion of EHNA/NBMPR in a model of the off-pump beating heart provides sitespecific protection at the ischemic vascular bed and wherever oxidative stress might occur during surgery. Targeting post-MI reperfusion injury with EHNA/NBMPR has important clinical potential in cases of post-MI thrombolytic therapy, stenting, and CABG.

\section{Study Limitations}

The present study had the obvious experimental model limitations that must be considered, including species-, age-, and model-related differences. The issue of the species-dependent presence of xanthine oxidase remains debatable. However, it is believed that the porcine heart resembles the human anatomy and coronary distribution. Also, some concerns have been recognized regarding the utility of color microspheres to measure myocardial blood flow because of the loss of microspheres and the yield of color recovery during extraction of microspheres and colors and analysis. Another limitation was the use of loaddependent estimates of regional function. Echocardiography would be more appropriate to monitor global function in the presence of a significant MI. Finally, the doses of EHNA and NBMPR were used according to our previous reports $^{3,4}$ and were greater than the $\mathrm{K}_{\mathrm{i}}$ values $(0.05 \mathrm{nM})$. The dose-response relationship was not intended in this canine model of MI. The timing of the administration of EHNA/NBMPR was considered to target post-MI reperfusion injury compared with before MI treatment.

E-Limitations are published on line.

\section{CONCLUSIONS}

The es-ENT1 transporter plays a crucial role in purinemediated reperfusion injury and that pharmacologic targeting of this transporter attenuates VFib and regional dysfunction in the presence of MI. Pre- and postconditioning with EHNA/NBMPR in a model of beating heart cardiac surgery has obvious clinical relevance to the setting of elective or emergent thrombolytic therapy, percutaneous coronary intervention, and CABG.

\section{References}

1. Braunwald E, Kloner RA. Myocardial reperfusion: a double-edged sword? J Clin Invest. 1985;76:1713-9.

2. Abd-Elfattah A, Higgins R, Latifi R, Merrell R. Targeting post-ischemic reperfusion injury: scientific dream and clinical reality. New Surg. 2001;1:41-51.

3. Abd-Elfattah AS, Jessen ME, Lekven J, Doherty NE III, Brunsting LA, Wechsler AS. Myocardial reperfusion injury: role of myocardial hypoxanthine and xanthine in free radical-mediated reperfusion injury. Circulation. 1988;78 III224-35.

4. Abd-Elfattah AS, Ding M, Wechsler AS. Intermittent aortic cross clamping prevents cumulative adenosine triphosphate depletion, ventricular fibrillation, and dysfunction (stunning): is it preconditioning? J Thorac Cardiovasc Surg. 1995; 110:328-39.

5. Abd-Elfattah AS, Jessen ME, Wechsler AS. Nucleoside trapping during reperfusion prevents ventricular dysfunction, "stunning," in absence of adenosine: possible separation between ischemic and reperfusion injury. J Thorac Cardiovasc Surg. 1994;108:269-78.

6. Zughaib ME, Abd-Elfattah AS, Jeroudi MO, Sun JZ, Sekili S, Tang XL, Bolli R. Augmentation of endogenous adenosine attenuates myocardial "stunning" independently of coronary flow or hemodynamic effects. Circulation. 1993;88(5 Pt 1):2359-69

7. Abd-Elfattah AS, Hoehner J, Wechsler AS. Identification of nucleoside transport binding sites in the human myocardium. Mol Cell Biochem. 1998;180:105-10.

8. Lu H, Chen C, Klaassen C. Tissue distribution of concentrative and equilibrative nucleoside transporters in male and female rats and mice. Drug Metab Dispos. 2004;32:1455-61.

9. Handa M, Choi DS, Caldeiro RM, Messing RO, Gordon AS, Diamond I. Cloning of a novel isoform of the mouse NBMPR-sensitive equilibrative nucleoside transporter (ENT1) lacking a putative phosphorylation site. Gene. 2001;262: $301-7$.

10. Rose JB, Naydenova Z, Bang A, Eguchi M, Sweeney G, Choi DS, et al. Equilibrative nucleoside transporter 1 plays an essential role in cardioprotection. Am J Physiol Heart Circ Physiol. 2010;298:H771-7.

11. Ishikawa K, Ogawa I, Shimizu M, Koka H, Kamata N, Nakai S, et al. The importance of good endocardial reflow immediately after reperfusion for myocardial salvage in dogs. Jpn Circ J. 1991;55:983-93

12. Mahgoub MA, Guo JH, Gao SP, Taher MM, Salter DD, Wechsler AS, et al. Hyperdynamic circulation of arteriovenous fistula preconditions the heart and limits infarct size. Ann Thorac Surg. 1999;68:22-8.

13. Murry CE, Jennings RB, Reimer KA. Preconditioning with ischemia: a delay of lethal cell injury in ischemic myocardium. Circulation. 1986;74:1124-36.

14. Zhao ZQ, Corvera JS, Halkos ME, Kerendi F, Wang NP, Guyton RA, et al. Inhibition of myocardial injury by ischemic postconditioning during reperfusion: comparison with ischemic preconditioning. Am J Physiol Heart Circ Physiol. 2003;285:H579-88.

15. Liu GS, Thornton J, Van Winkle DM, Stanley AW, Olsson RA, Downey JM. Protection against infarction afforded by preconditioning is mediated by A1 adenosine receptors in rabbit heart. Circulation. 1991;84:350-6.

16. Kin H, Zatta AJ, Lofye MT, Amerson BS, Halkos ME, Kerendi F, et al. Postconditioning reduces infarct size via adenosine receptor activation by endogenous adenosine. Cardiovasc Res. 2005;67:124-33

17. Walsh RS, Abd-Elfattah AS, Daly JJF, Wechsler AS, Downey J. Selective blockade of nucleoside transport channels prevents preconditioning of rabbit myocardium. Surg Forum. 1993;XLIV:234-6.

18. Walsh SR, Abd-Elfattah AS, Daly JJF, Wechsler AS, Downy J. Nucleoside transport prevents ischemic preconditioning (abstract). Circulation. 1993;88(Suppl): I-432.

19. Grube K, Rüdebusch J, Xu Z, Böckenholt T, Methner C, Müller T, et al. Evidence for an intracellular localization of the adenosine A2B receptor in rat cardiomyocytes. Basic Res Cardiol. 2011;106:385-96.

20. Abd-Elfattah AS, Ding M, Jessen ME, Wechsler AS. On-pump inhibition of es-ENT1 nucleoside transporter and adenosine deaminase during aortic crossclamping entraps intracellular adenosine and protects against reperfusion injury: role of adenosine A1 receptor. J Thorac Cardiovasc Surg. 2012;144 243-9.

21. Xi J, McIntosh R, Shen X, Lee S, Chanoit G, Criswell H, et al. Adenosine A2A and $\mathrm{A} 2 \mathrm{~B}$ receptors work in concert to induce a strong protection against reperfusion injury in rat hearts. J Mol Cell Cardiol. 2009;47:684-90.

22. Urmaliya VB, Pouton CW, Ledent C, Short JL, White PJ. Cooperative cardioprotection through adenosine $\mathrm{A} 1$ and $\mathrm{A} 2 \mathrm{~A}$ receptor agonism in ischemia-reperfused isolated mouse heart. J Cardiovasc Pharmacol. 2010;56:379-88.

23. Mentzer RM Jr, Birjiniuk V, Khuri S, Lowe JE, Rahko PS, Weisel RD, et al. Adenosine myocardial protection: preliminary results of a phase II clinical trial. Ann Surg. 1999;229:643-9.

24. Ross AM, Gibbons RJ, Stone GW, Kloner RA, Alexander RW, AMISTAD-II Investigators. A randomized, double-blinded, placebo-controlled multicenter trial of adenosine as an adjunct to reperfusion in the treatment of acute myocardial infarction (AMISTAD-II). J Am Coll Cardiol. 2005;45:1775-80. 


\section{E-METHODS}

Surgical Procedures and Model of Acute MI

A total of 37 microfilaria-free adult dogs, of either sex and weighing $22.3 \pm 2 \mathrm{~kg}$, were used in the present study. The dogs were anaesthetized with an intravenous injection of $35 \mathrm{mg} / \mathrm{kg}$ sodium pentobarbital (Abbott Laboratories, Chicago, Ill), intubated, and ventilated using a Bennett MA1 respirator (Puritan-Bennett, Berkeley, Calif). Additional doses of $10 \mathrm{mg} / \mathrm{kg}$ sodium pentobarbital were injected as needed to maintain anesthesia. A median sternotomy was performed, and the heart was supported in a pericardial sling. The anterior (ischemic) and posterior (nonischemic) segments of the left ventricle were instrumented with 2 pairs of lead titanate zirconate piezoelectric crystals to monitor systolic segmental shortening and systolic wall thickening using a pulse transit sonomicrometry system (Triton Technology, San Diego, Calif). Micromanometer balloon-tipped catheters (Millar Instruments, Houston, Tex) were placed intraventricularly by way of the apex and into the carotid artery to monitor the left ventricular and systemic pressures, respectively. The analog data were digitized at $200 \mathrm{~Hz}$ and stored on a hard disk on a personal computer. Subsequent analysis was performed using interactive Crunch software developed in our laboratory. Regional myocardial contractility and wall thickening were measured at varying preloads, as previously described. ${ }^{\mathrm{E} 1}$ The body temperature was maintained constant with heating pads, and the myocardial temperature was kept at $37^{\circ} \pm 1^{\circ} \mathrm{C}$. A fluid supplement was given as an intravenous drip. A silastic snare was placed around the left anterior descending artery just before the first diagonal branch. The right phrenic nerve was transected to eliminate diaphragmatic contractions. The sinoatrial node was crushed, and the heart atrially paced at $150 \mathrm{bpm}$ using a Medtronic 5880A pacemaker (Medtronic, Minneapolis, Minn). The rationale for electrical pacing of hearts is to minimize variations in the heart rates among dogs of the same group and between groups. Porcine-based heparin was injected intravenously (400 U/kg) as an initial bolus followed by $200 \mathrm{U} / \mathrm{kg} / \mathrm{hr}$ (Elkins-Sinn, Cherry Hill, NJ). Arterial blood gases, $\mathrm{pH}$, and hematocrit were routinely determined and maintained (partial oxygen pressure, $100-140 \mathrm{~mm} \mathrm{Hg}$; partial carbon dioxide pressure, $30-40 \mathrm{~mm} \mathrm{Hg}$; $\mathrm{pH}, 7.32-7.48$; and hematocrit, about $30 \%)$.

\footnotetext{
Assessment of Adenine Nucleotide Pool Metabolism

Myocardial adenine nucleotides (adenosine triphosphate [ATP], adenosine diphsophate, and adenosine monophosphate), adenine nucleosides (adenosine and inosine), purine bases (hypoxanthine and xanthine), and nicotinamide adenine dinucleotide $\left(\mathrm{NAD}^{+}\right)$were determined at baseline, during 90 minutes of left anterior descending artery occlusion and 120 minutes of reperfusion. Transmural Tru-Cut needle (Travenol Laboratories, Deerfield, Ill) biopsy specimens $(5-10 \mathrm{mg})$ were obtained at baseline before and after drug administration. Serial biopsies were obtained during $90 \mathrm{~min}-$ utes of normothermic ischemia and 120 minutes of reperfusion. Each biopsy was immediately frozen and stored in liquid nitrogen $\left(-196^{\circ} \mathrm{C}\right)$. Each biopsy specimen was extracted, neutralized, and analyzed using high-performance liquid chromatography, as previously described, ${ }^{\mathrm{E} 2, \mathrm{E} 3}$ and the values were normalized per milligram protein.
}

\section{Measuring Coronary Flow With Colored Microspheres}

Measurements of regional coronary flow were performed as previously described $^{\mathrm{E} 4}$ before and during ischemia. Fluorescent-labeled microspheres (15 $\mu \mathrm{m}$ in diameter) were injected into the left atrium of the anesthetized dogs, and reference blood samples were simultaneously withdrawn from a femoral artery. At the end of each study, each heart was weighed and transmurally cubed and divided into the epicardium and endocardium and accurately weighed. The tissue samples and reference blood samples were digested with potassium hydroxide and filtered, and the fluorescent dye was extracted with dimethylformamide as a solvent. The fluorescence of each sample was determined for each color using an automated spectrophotometer. The coronary blood flow was expressed as the mean milliliters per minute per gram of tissue weight of the transmural sections of the myocardium.

\section{Tissue Histologic Examination}

Tissue samples (200-400 mg) were obtained at the end of each study from the ischemic and nonischemic segments of the left ventricle and fixed in glutaraldehyde and prepared for thin sectioning and electron microscope analysis, as previously described by Hayte. The samples were analyzed by a histologist (H.A.) who was unaware of the groups.

\section{Myocardial NAD}

Figure 4 shows the effects of acute myocardial ischemia and reperfusion on tissue $\mathrm{NAD}^{+}$in all groups. At baseline, all groups had similar $\mathrm{NAD}^{+}$ levels. The decline in myocardial $\mathrm{NAD}^{+}$was more pronounced $(50 \%)$ in the untreated control group (from $3.7 \pm 0.3$ to $1.8 \pm 0.3 \mathrm{nmol} / \mathrm{mg}$ protein, about a $50 \%$ reduction from baseline) during ischemia and continued to decline to $1.4 \pm 0.2$ and $1.2 \pm 0.2 \mathrm{nmol} / \mathrm{mg}$ protein $(59 \%$ and $63 \%$ ) during 30 and 120 minutes of reperfusion. In the preconditioning and postconditioning groups, the $\mathrm{NAD}^{+}$levels were maintained during ischemia and during reperfusion (Figure E2).

\section{E-References}

E1. Glower DD, Spratt JA, Snow ND, Kabas JS, Davis JW, Olsen CO, et al. Linearity of the Frank-Starling relationship in the intact heart: the concept of preload recruitable stroke work. Circulation. 1985;71:994-1009.

E2. Abd-Elfattah AS, Jessen ME, Lekven J, Doherty NE III, Brunsting LA, Wechsler AS. Myocardial reperfusion injury. Role of myocardial hypoxanthine and xanthine in free radical-mediated reperfusion injury. Circulation. 1988;78: III224-35.

E3. Abd-Elfattah AS, Wechsler AS. Superiority of HPLC to assay for enzymes regulating adenine nucleotidase pool intermediates metabolism: 5'-nucleotidase, adenylate deaminase, adenosine deaminase and adenylosuccinate lyase: A simple and rapid determination of adenosine. J Liquid Chromatogr. 1987;10: 2653-94.

E4. Mahgoub MA, Guo JH, Gao SP, Taher MM, Salter DD, Wechsler AS, AbdElfattah AS. Hyperdynamic circulation of arteriovenous fistula preconditions the heart and limits infarct size. Ann Thorac Surg. 1999;68:22-8. 

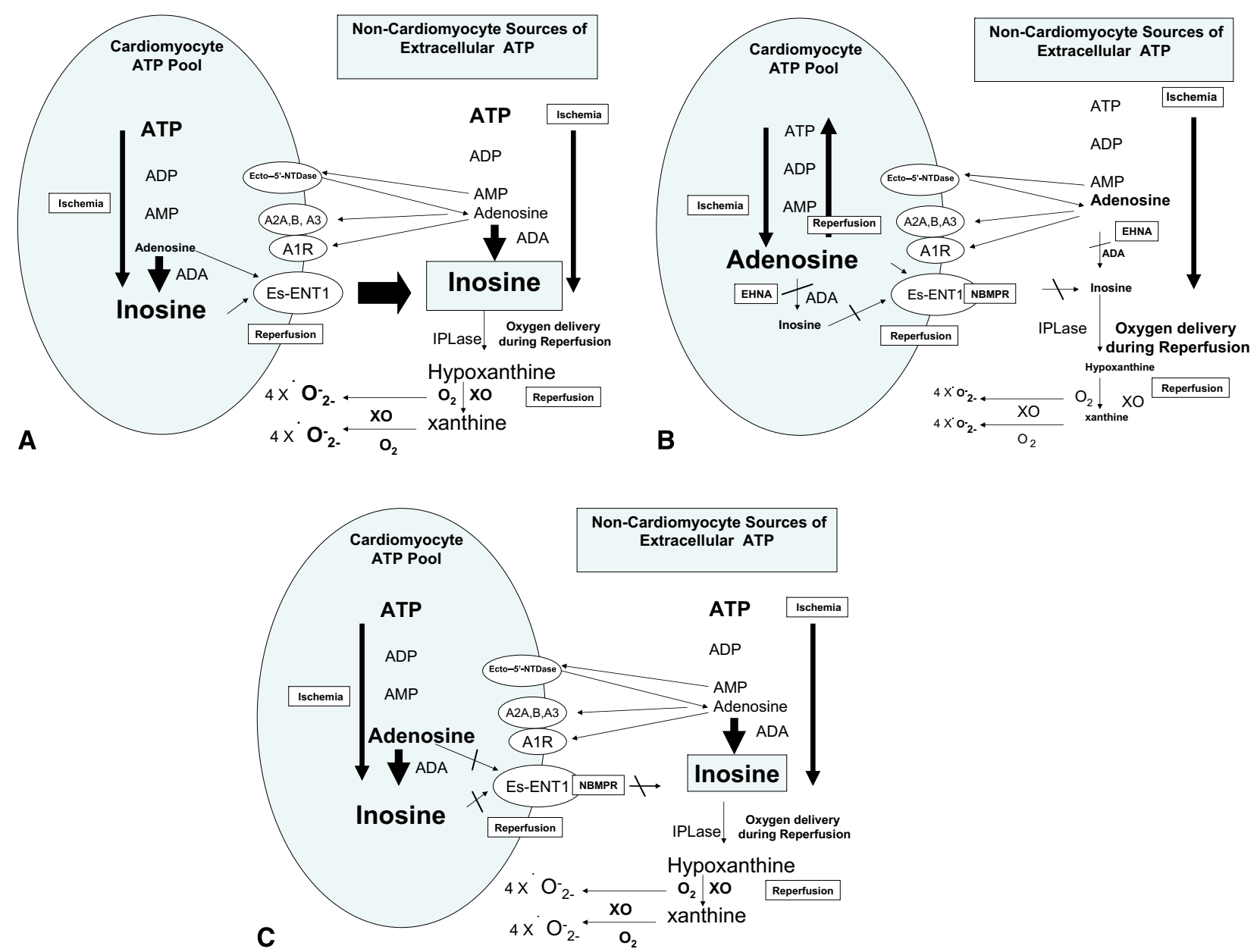

FIGURE E1. Role of adenine nucleosides metabolism and transport by way of es-NT1 (compartmentalization) in purine-mediated post-myocardial infarction reperfusion injury. The figure illustrates purine metabolism and compartmentalization in relation to ischemic and reperfusion injury in the untreated control group (A). Ischemia is associated with intracellular adenosine triphosphate (ATP) depletion. Sympathetic stimulation at the onset of ischemia results in neurotransmitter and ATP co-release, elevating extracellular ATP. Ecto- and endo-5'-nucleotidase (endo) and adenosine deaminase continue breaking down ATP and adenosine monophosphate (AMP) during ischemia to adenosine in the intracellular and extracellular compartments. Adenosine is rapidly deaminated to inosine by adenosine deaminase. Extracellular inosine is converted by inosine phosphorylase (IPLase) to hypoxanthine, and the latter is oxidized to xanthine and superoxide radicals during cardiac ischemia and reperfusion. Intracellular inosine and the remaining adenosine are rapidly released on reperfusion by way of the p-nitrobenzylthioinosine (NBMPR)-sensitive adenine nucleoside transporter-1 (es-ENT1), allowing abrupt formation of hypoxanthine, xanthine, and free radicals. The effect of preischemic treatment with EHNA/NBMPR of purine metabolism and compartmentalization is depicted in part B. Adenosine is maintained inside and outside cells. C, Effect of MI postconditioning with EHNA/NBMPR. Intracellular inosine is the major end product of ATP depletion during ischemia. Similar to the control group, noncardiac ATP is broken down to xanthine, producing free radicals in the circulation. Infusion of EHNA/NBMPR after MI but before releasing the left anterior descending coronary artery occlusion allowed entrapment of intracellular inosine, limiting the reperfusion injury mediated by free radicals. ADP, Adenosine diphosphate; $A M P$, adenosine monophosphate; ecto- $5^{\prime} N T D a s e, 5^{\prime}$-nucleotidase; es-ENT1, equilibrative p-nitro-benzylthioinosine (NBMPR)-sensitive adenine nucleoside transport 1; $A 1 R$, adenosine receptor 1; IPLase, inosine phosphorylase; $\mathrm{XO}$, xanthine oxidase; $\mathrm{O}_{2}$, molecular oxygen; $\mathrm{O}_{2}$, superoxide radical. The font size reflects the amount of purine at ischemia or reperfusion. 


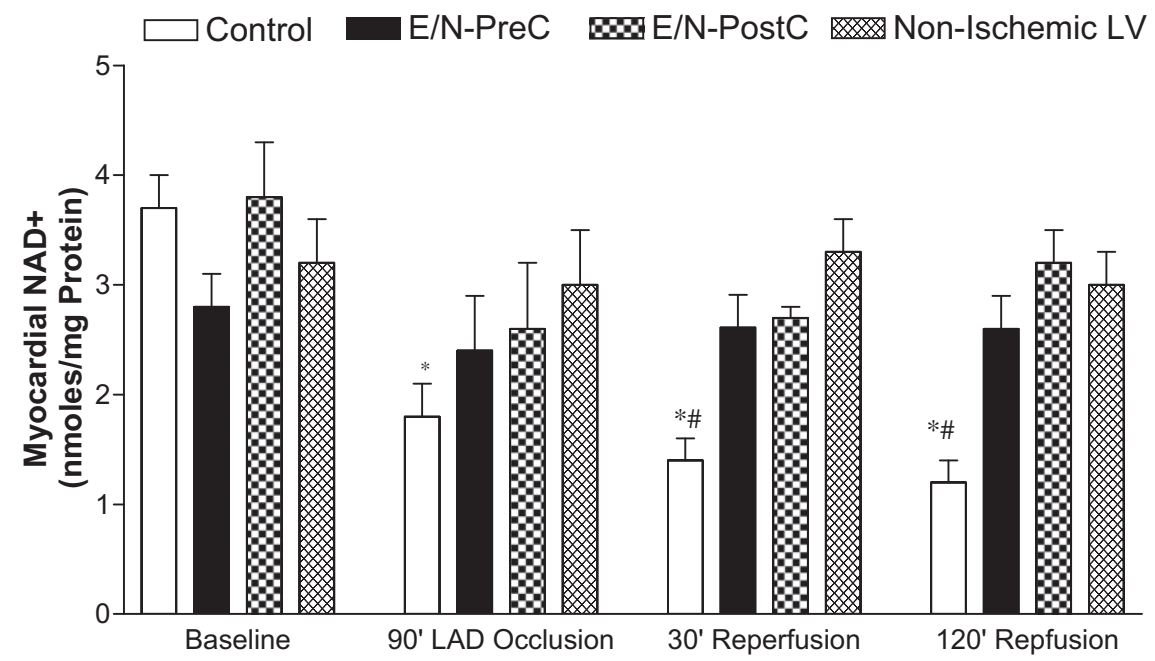

FIGURE E2. Effect of erythro-9 (2-hydroxy-3-nonyl)-adenine/p-nitrobenzylthioinosine (EHNA/NBMPR) on myocardial nicotinamide adenine dinucleotide (NAD+) in a canine model of 90 minutes left anterior descending $(L A D)$ atery occlusion and reperfusion. There was statistical significance between groups $(P<.05,2$-way analysis of variance). $* P<.05$ vs baseline and control group. $\# P<.05$ vs post-ischemic treatment group, analysis of variance, $\mathrm{n}=8$ dogs/each group. $L V$, Left ventricle.

TABLE E1. Reasons for excluding dogs from the study

\begin{tabular}{lccc}
\hline & & \multicolumn{2}{c}{ EHNA/NBMPR group (n) } \\
\cline { 3 - 4 } \multicolumn{1}{c}{ Reason } & $\begin{array}{c}\text { Control } \\
\text { group (n) }\end{array}$ & $\begin{array}{c}\text { Before } \\
\text { ischemia }\end{array}$ & $\begin{array}{c}\text { After } \\
\text { ischemia }\end{array}$ \\
\hline Fatal anesthesia & 1 & 0 & 1 \\
$\begin{array}{l}\text { Baseline hypotension or } \\
\text { tachycardia (>200 bpm) }\end{array}$ & 1 & 2 & 0 \\
$\begin{array}{l}\text { Significant collateral flow } \\
\quad>20 \% \text { during LAD }\end{array}$ & 3 & 2 & 2 \\
$\quad$ occlusion) & & & \\
Total excluded dogs (n) & $5(31.3 \%)$ & $4(36.4 \%)$ & $3(27.3 \%)$ \\
Total dogs possible (n) & 13 & 11 & 11 \\
Dogs used (n) & $8(61.5 \%)$ & $8(66.7 \%)$ & $8(72.7 \%)$ \\
\hline $\begin{array}{l}E H N A / N B M P R, \text { Erythro-9 (2-hydroxy-3-nonyl)-adenine; NBMPR, p-nitrobenzylth- } \\
\text { ioinosine; } L A D \text {, left anterior descending (artery). }\end{array}$
\end{tabular}

